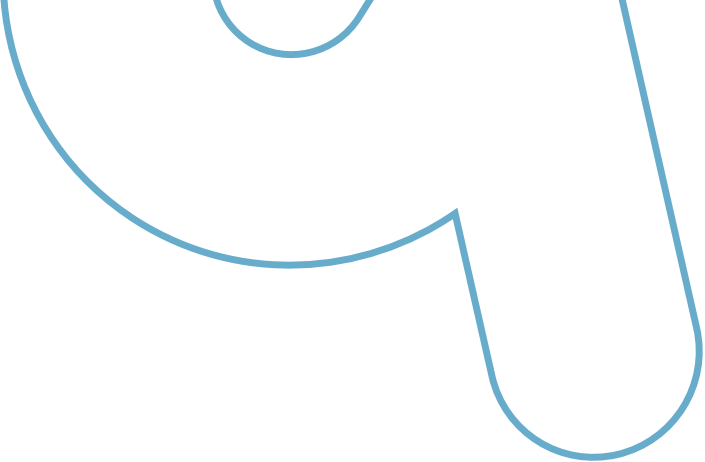

\title{
Proposta de metodologia para o aproveitamento de resíduos no design de superfície
}

Proposal of a methodology for the use of solid waste in surface

design

\section{Danieli Maehler Nejeliski}

Instituto Federal Sul-Rio-Grandense

danielinejeliski@gmail.com

\.

\section{Lauren da Cunha Duarte}

Universidade Federal do Rio Grande do Sul

lauren.duarte@ufrgs.br

\section{PROJËTICA}

\section{COMO CITAR ESTE ARTIGO:}

NEJELISKI, Danieli Maehler; DUARTE, Lauren da Cunha. Proposta de metodologia para o aproveitamento de resíduos no design de superfície. Projética, Londrina, v. 12, n. 2, p. 13-38, 2021.

DOI: 10.5433/2236-2207.2021v12n2p13

Submissão: 25-03-2020

Aceite: $07-05-2020$ 
RESUMO: A geração de resíduos sólidos no Brasil aumenta a cada ano. O design de superfície pode ser uma alternativa para o desenvolvimento de produtos com maior valor agregado a partir destes materiais. O objetivo do trabalho é propor uma metodologia para potencializar o uso de resíduos sólidos no desenvolvimento de projetos de design de superfície. A metodologia é dividida em três etapas: caracterização, otimização e aplicação. A caracterização envolve a definição e a classificação dos resíduos, a especificação das propriedades e dos diferenciais estéticos. A otimização envolve o aproveitamento dos resíduos, a experimentação e o esboço dos módulos. Por fim, a aplicação envolve as especificações técnicas, a produção dos módulos e a aplicação em produtos. O foco desta metodologia é a valorização dos resíduos como matéria-prima, por meio de projetos de superfícies tridimensionais.

Palavras-chave: Resíduos sólidos. Design de superfície. Metodologia. Propriedades sensoriais.

ABSTRACT: The solid waste generation in Brazil increases every year. Surface design can be an alternative for the development of products with greater added value from the use of those materials. The objective of this work is to propose a methodology to enhance the use of solid waste in the development of surface design projects. The methodology is divided into three stages: characterization, optimization, and application. Characterization involves the definition and classification of waste, the specification of properties and aesthetic attributes. Optimization involves the use of waste, experimentation, and modular design. Finally, the application involves technical specifications, production, and application of the modules in products. This methodology focuses on the valorisation of waste as raw material, through three-dimensional surface projects.

Keywords: Solid waste. Surface design. Methodology. Sensorial properties. 
Proposta de metodologia para o aproveitamento...design de superfície

\section{INTRODUÇÃO}

Toda atividade humana gera resíduos, são os rastros que deixamos no planeta. Eles vão desde os inerentes à condição humana, oriundos de necessidades básicas, até os resultantes dos mais complexos processos industriais. Trata-se de uma cadeia extremamente complexa em que o usuário é o elo final. Antes do descarte, uma série de outros resíduos é gerada ao longo de todos os processos pelos quais o produto passa. Os resíduos sólidos são materiais, produtos ou partes destes, resultantes das atividades humanas, cuja destinação final inclui a reutilização, a reciclagem, a compostagem, a recuperação e o aproveitamento energético (BRASIL, 2010). Assim, todo resíduo sólido que é descartado irregularmente é um desperdício, pois tem potencial para ser utilizado como matéria-prima na produção de outros produtos.

No Brasil, no ano de 2018, foram geradas 79 milhões de toneladas de resíduos sólidos urbanos, que incluem os resíduos domésticos e de limpeza urbana. O que se observa é que a geração de lixo no Brasil aumenta, enquanto a infraestrutura para a destinação adequada não acompanha este crescimento (ABRELPE, 2019). Um dos desafios do design para a sustentabilidade é o desenvolvimento de alternativas para a redução do volume de resíduos sólidos descartada precoce e incorretamente. Devido às características específicas de cada classe de material, nem todos os resíduos podem ser reutilizados ou reciclados. Uma alternativa para o aproveitamento destes materiais é na produção de produtos com maior valor agregado (PMVA), uma solução paliativa dentro da hierarquia dos resíduos. Considerando as características heterogêneas dos resíduos sólidos e a importância da valorização de suas propriedades sensoriais no projeto, a abordagem do design de superfície é uma alternativa para o desenvolvimento de PMVA.

O design de superfície é uma atividade criativa e técnica que tem como objetivo o desenvolvimento de qualidades estéticas, funcionais e estruturais, a partir do projeto para a constituição de superfícies (RUTSCHILLING, 2009). Para 
Projética, Londrina, v. 12, n. 2, p. 13-38, agosto 2021

Um dos desafios do design para a sustentabilidade é o desenvolvimento de alternativas para a redução do volume de resíduos sólidos descartada precoce e incorretamente.

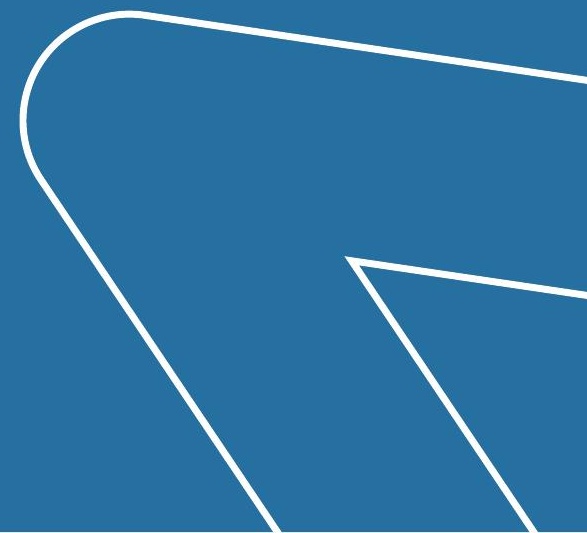


Proposta de metodologia para o aproveitamento...design de superfície

Manzini (1993) o sistema da superfície proporciona aos objetos desempenhos que vão desde os mais óbvios, como proteção às agressões e qualidades estéticas e sensoriais, até a transformação da superfície em um meio de comunicação. Cardoso (2008) enfatiza que o design de superfície foi uma das primeiras práticas profissionais no campo do design. Nos primórdios da organização industrial os designers eram contratados pelas indústrias para criar padrões para a impressão mecânica contínua de tecidos. Os padrões eram desenvolvidos uma única vez e possibilitavam a reprodução ilimitada com qualidade.

Com a evolução tecnológica de materiais e processos produtivos, o design de superfície se estabelece como campo investigativo abrangente e recurso diferenciador, podendo se agregar ao projeto dos mais diversos produtos. As soluções estéticas do design de superfície são exploradas tanto em projetos bidimensionais quanto em tridimensionais. A valorização das características intrínsecas dos materiais e das propriedades sensoriais fornecem uma série de elementos a serem explorados, como cores, figuras, elementos de ritmo e texturas. Tais características também são importantes para a identificação dos materiais pelos usuários.

O êxito de qualquer projeto de design depende do uso de uma metodologia adequada às particularidades do contexto do projeto. O planejamento requer a identificação das atividades a serem desenvolvidas, sequência e simultaneidade dessas atividades, tempo e recursos necessários, responsabilidade pelas atividades, início e conclusão do projeto (BACK et al., 2008). O design de superfície é uma área abrangente, com aplicações diversas nas áreas do design digital, gráfico e de produto. Assim, metodologias para o projeto de superfícies de uma área específica, podem não ser adequadas para as demais. Nesse contexto, o objetivo do trabalho é propor uma metodologia para potencializar o aproveitamento dos resíduos sólidos no desenvolvimento de projetos a partir da abordagem do design de superfície. 


\section{RESÍDUOS SÓLIDOS E O PAPEL DO DESIGN}

O ciclo dos resíduos está diretamente relacionado ao ciclo de vida dos produtos.A Política Nacional de Resíduos Sólidos - PNRS (BRASIL, 2010) define o ciclo de vida dos produtos como uma série de etapas que envolvem a obtenção de matérias-primas e insumos, o desenvolvimento, o processo produtivo, o consumo e a disposição final. Para Manzini e Vezzoli (2008) está relacionado com os fluxos de matéria, energia e emissões que ocorrem ao longo de todas as etapas. A figura 1 mostra as etapas do ciclo de vida dos produtos - pré-produção, produção, distribuição, uso e eliminação - e as atividades dentro de cada etapa. Os fluxos são representados como outputs e inputs, as trocas com o meio ambiente.

Figura 1 - Ciclo de vida sistema-produto

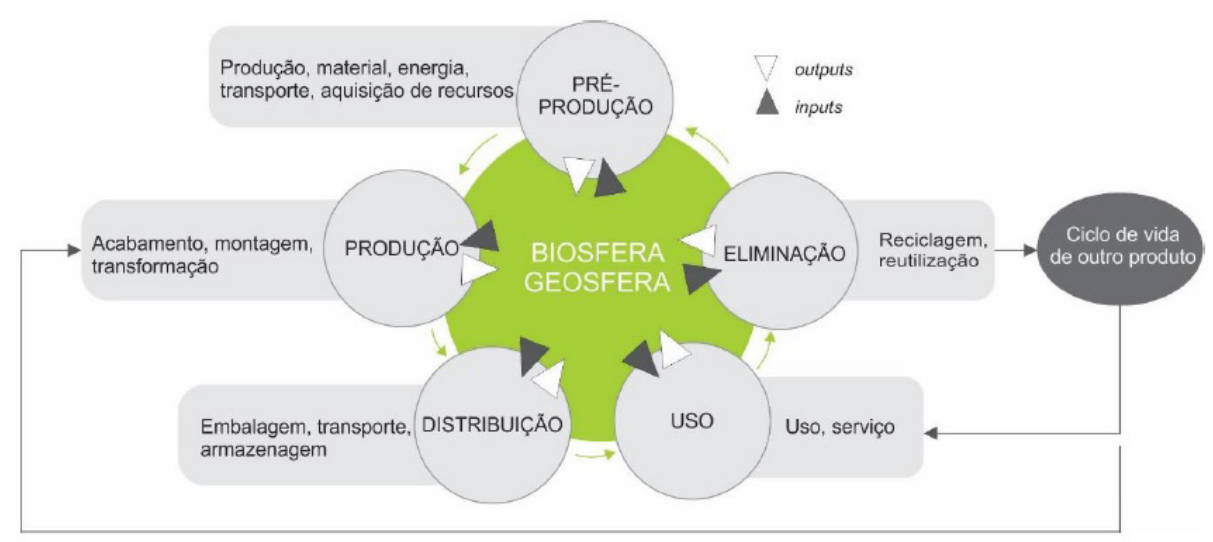

Fonte: Ashton (2017), adaptado de Manzini e Vezzoli (2008).

Os inputs representam a matéria e a energia necessárias para a produção, extraídas do meio ambiente ou de fontes intermediárias. Já os outputs representam as emissões liberadas na natureza ao final de cada ciclo, os resíduos das transformações das matérias-primas. Manzini e Vezzoli (2008) enfatizam a importância do projeto do ciclo de vida do produto, onde são analisados todos 
Proposta de metodologia para o aproveitamento...design de superfície

os impactos causados ao longo de todas as etapas e propostas soluções para mitigá-los. Ashton (2017) ressalta que em muitos casos, a determinação do nível de sustentabilidade de um material não é inerente ao material em si, mas à gestão do seu ciclo de vida.

Os outputs são resíduos que podem ser sólidos, líquidos ou gasosos, dependendo da natureza da atividade da qual se originam. O foco deste trabalho está nos resíduos sólidos, é importante diferenciá-los dos rejeitos. Resíduo sólido é o material, substância, objeto ou bem descartado, resultante de atividades humanas em sociedade, cuja destinação final se propõe proceder nos estados sólido ou semissólido. Já os rejeitos são resíduos sólidos que, depois de esgotadas todas as possibilidades de tratamento e recuperação por processos disponíveis e economicamente viáveis, não apresentam outra possibilidade que não a disposição final ambientalmente adequada (BRASIL, 2010).

Nesse contexto, para os resíduos sólidos a destinação final inclui a reutilização, a reciclagem, a compostagem, a recuperação e o aproveitamento energético, observando normas específicas de modo a evitar riscos à saúde pública e impactos ambientais adversos. Já para os rejeitos, a disposição final ambientalmente adequada é a distribuição ordenada em aterros, observando normas operacionais específicas (BRASIL, 2010). Proporcionalmente, a sociedade produz e descarta mais resíduos sólidos do que rejeitos, de modo que a maior parte do volume de material que chega aos aterros tem potencial para ser reaproveitado. Os resíduos sólidos são uma categoria de matérias-primas a parte, com potencial a ser explorado.

Ashton (2018), em um estudo de gerenciamento de resíduos sólidos na indústria calçadista, observou que a redução no custo de produção pode ser alcançada através da diminuição na aquisição de matérias-primas e da redução dos custos de disposição de resíduos. A hierarquia dos resíduos é uma ferramenta para 
auxiliar no projeto do ciclo de vida dos produtos e, principalmente, no gerenciamento dos resíduos. Propõe ações de caráter amplo, em ordem decrescente de impacto ambiental. Inicia com a proposta de reduzir e, se possível, eliminar a fonte dos resíduos, e finaliza com o descarte dos rejeitos em aterros. A proposta é condizente com a afirmação de Manzini e Vezzoli (2008) de que a atuação do design deve ser pautada na construção de cenários sustentáveis, não apenas de produtos menos poluentes.

A hierarquia dos resíduos é organizada em três etapas (figura 2). A primeira é preventiva, onde a utilidade e a necessidade do produto são questionadas. Caso o produto seja mantido ou produzido, o objetivo é a redução do gasto de energia e matéria-prima em todas as etapas do processo. A etapa seguinte é paliativa, apresenta soluções para o fim da vida útil do produto e dos materiais. As alternativas são a reutilização, reciclagem ou PMVA. A terceira e última etapa está relacionada com o descarte dos rejeitos, excluídas todas as possibilidades de aproveitamento dos resíduos sólidos. Os rejeitos podem ser utilizados para a recuperação energética ou descartados em aterros.

Figura 2 - Hierarquia dos resíduos

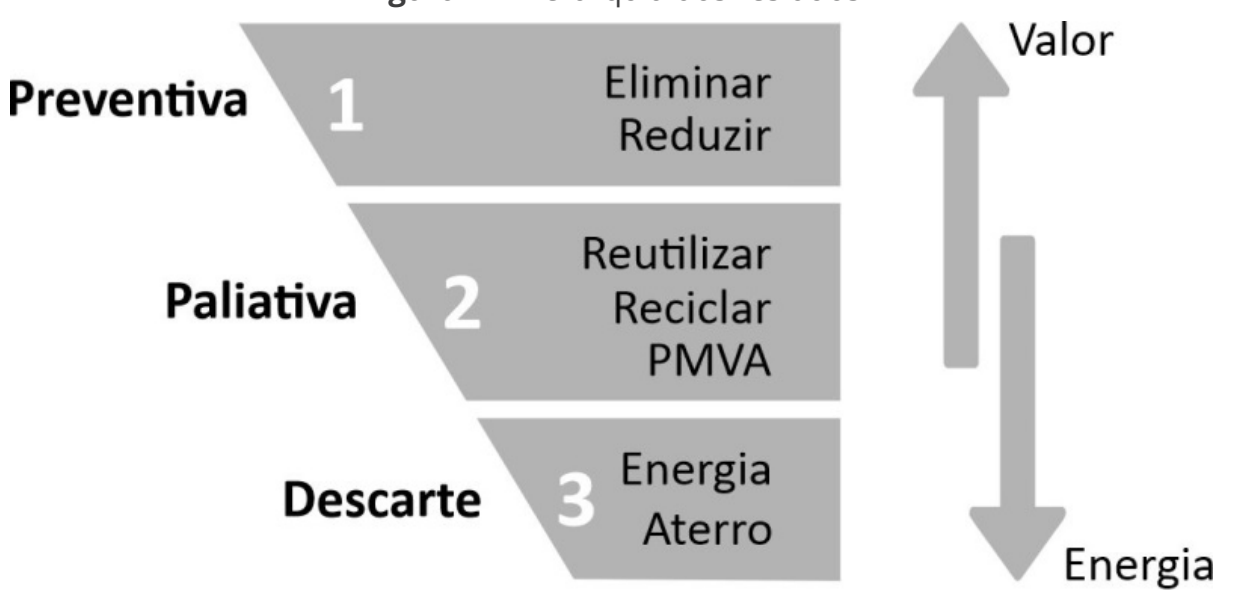

Fonte: Adaptado de Gomes (2011). 
Proposta de metodologia para o aproveitamento...design de superfície NEJELISKI, D. M.; DUARTE, L. da C.

A sociedade produz e descarta mais resíduos sólidos do que rejeitos, de modo que a maior parte do volume de material que chega aos aterros tem potencial para ser reaproveitado.

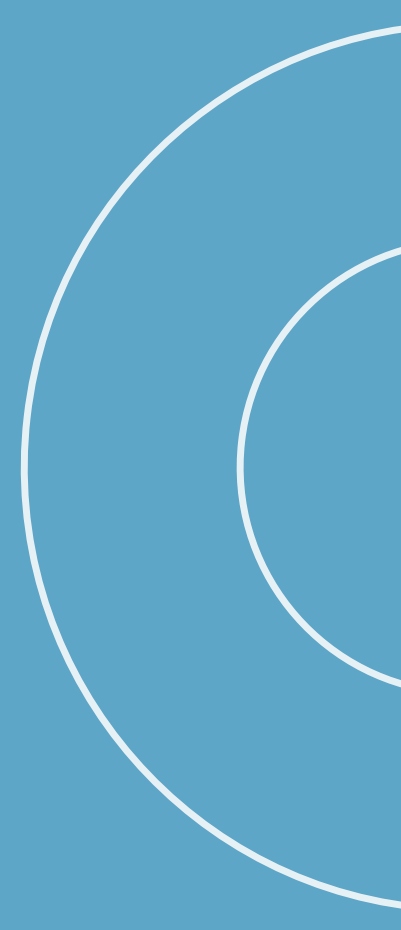


$\mathrm{Na}$ hierarquia dos resíduos as escalas de energia e valor atuam em sentidos opostos. Enquanto que a energia gasta nos processos aumenta em ordem crescente, o valor agregado aumenta em ordem decrescente. Essa relação se aplica entre as etapas e dentro de cada delas. Na escala de energia, o gasto na etapa preventiva é menor que na paliativa, que é menor que na de descarte. Eliminar um produto gasta menos energia que desenvolver um projeto pautado na redução. Do mesmo modo, reutilizar gasta menos energia que reciclar, e menos que desenvolver um novo PMVA. O mesmo vale para a escala de valor, enquanto que os rejeitos não possuem valor agregado, as soluções paliativas valorizam o produto e as soluções de prevenção resultam no maior valor agregado dentre as três etapas.

A primeira etapa, preventiva, tem caráter mais amplo e atua na construção de cenários sustentáveis, propõe a análise e a reflexão da estrutura do sistema de consumo tradicional e destaca o papel do design na concretização de ações com menor impacto ambiental. Dentro desta etapa, as alternativas são a eliminação do produto ou a redução de energia e materiais associados. A estratégia mais eficaz para lidar com os resíduos é a eliminação, se deixarmos de produzir e usar algo, os resíduos que lhe estão associados deixam de existir. Entretanto, esta alternativa nem sempre é viável, de tal modo que o projeto pautado na redução por si só diminui consideravelmente o volume de resíduos nos processos.

A segunda etapa, paliativa, engloba a reutilização, a reciclagem e o produto com maior valor agregado. Na definição da melhor opção deve-se considerar a tríade para o entendimento do escopo de aplicação dos materiais: estrutura, propriedades e processamento (WALTER, 2006). Dependendo das características das matérias-primas, ao fim da vida útil o produto poderá passar por um, dois ou mesmo pelos três ciclos, sistematicamente. Na reutilização os produtos são utilizados novamente sem gasto energético ou alterações na matéria- prima, inteiros ou desmontados. Os tipos de reutilização são a direta, na mesma função; a renovação, onde é realizada a limpeza e outras melhorias; a reparação, onde é 
Proposta de metodologia para o aproveitamento...design de superfície

realizada a reparação de falhas e defeitos; a reafectação, que é a utilização em outras funções; e, por fim, a remanufatura, que é um processo mais complexo, onde um novo produto é produzido a partir do antigo (GOMES, 2011).

A reciclagem é um processo de transformação dos resíduos sólidos que envolve a alteração das propriedades físicas, físico-químicas ou biológicas, transformando-os em novos produtos e reinserindo-os no mercado. Os resíduos são triturados, fundidos e extrudidos em novas formas e o material reciclado deverá apresentar qualidade suficientemente alta para ser usado novamente na mesma aplicação (GOMES, 2011). Neste aspecto, é imprescindível o conhecimento a respeito da vida útil dos materiais após diversos ciclos de reciclagem, pois o mesmo auxilia no processo de seleção de materiais sustentáveis e no gerenciamento do ciclo fechado (CÂNDIDO et al., 2011).

Para alguns produtos e materiais a reutilização e a reciclagem não são viáveis, mas antes de serem classificados como rejeito e passarem para a etapa de descarte, podem ser utilizados na produção de produtos com maior valor agregado. É uma alternativa, por exemplo, para os resíduos de materiais naturais como a madeira, o bambu e as fibras vegetais. O design de produto é o principal diferencial neste processo, transformando matérias-primas com pouco ou nenhum valor agregado em produtos sustentáveis e criando uma cadeia de geração de valor.

A terceira etapa é de descarte e envolve a recuperação energética e o descarte em aterros. A recuperação energética se dá através da incineração dos rejeitos em centrais de gestão de resíduos, onde as emissões são controladas e o calor gerado é aproveitado na geração de energia. Já o aterro sanitário é uma obra de engenharia, projetada com o objetivo de tratar os rejeitos após esgotadas todas as possibilidades de reaproveitamento. O solo é revestido com um material impermeável, a estrutura é organizada em camadas sobrepostas, possui um sistema de drenagem e os gases gerados são queimados e geram energia. 0 
descarte de resíduos sólidos e rejeitos em lixões está proibido no Brasil por lei (BRASIL, 2010), entretanto ainda vigora em grande parte das cidades brasileiras. A realidade é que o maior volume de material descartado é de resíduos sólidos, sem separação prévia, que acaba prejudicando o processo de decomposição do material orgânico associado. Não obstante, o descarte de resíduos sólidos é um desperdício de matéria-prima e uma oportunidade perdida de geração de emprego e renda.

\section{DESIGN DE SUPERFÍCIE}

O design de superfície é uma atividade essencialmente projetual, que atribui características perceptivas expressivas à superfície dos objetos, por meio de texturas visuais, táteis e relevos, e tem como objetivo estabelecer interações sensório-cognitivas entre o objeto e o sujeito (SCHWARTZ; NEVES; RUTSCHILLING, 2008). A função do design de superfície é agregar valor aos produtos, valor afetivo a partir da estética, cores e materiais, valores regionais e culturais por meio dos motivos apresentados nas superfícies, comunicação de ideias, tendências. Ainda, o design de superfície revela e enfatiza funções que antes eram despercebidas ou não eram consideradas fundamentais para a qualidade ou sucesso do produto perante o usuário (RINALDI, 2013).

Os elementos visuais apresentam funções que podem se manifestar de diferentes maneiras, sendo as principais como figuras ou motivos, elementos de preenchimento e elementos de ritmo. Figuras ou motivos são formas nãointerrompidas, que aparecem em primeiro plano, são recorrentes na composição, podem apresentar variações e dão sentido à composição. Os elementos de preenchimento são texturas e grafismos que preenchem os diferentes planos, criando uma ligação visual e tátil entre os elementos. Já os elementos de ritmo possuem mais força visual que os demais, o que é alcançado pela configuração, posição, cor e outros aspectos dos elementos no espaço (RÜTHSCHILLING, 2009). 


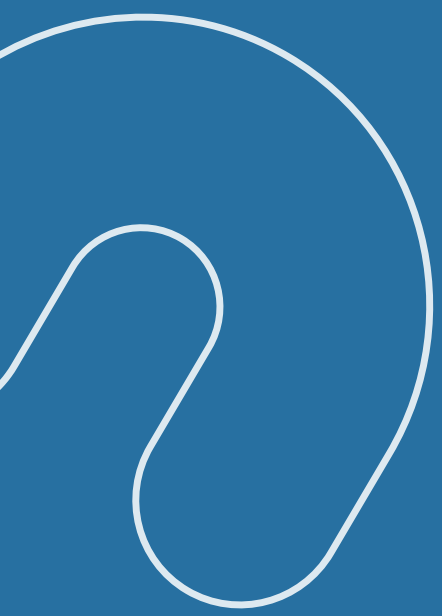

Proposta de metodologia para o aproveitamento...design de superfície NEJELISKI, D. M.; DUARTE, L. da C.

"A função do design de superfície é agregar valor aos produtos, valor afetivo a partir da estética, cores e materiais, valores regionais e culturais por meio dos motivos apresentados nas superfícies, comunicação de ideias, tendências. Ainda, o design de superfície revela e enfatiza funções que antes eram despercebidas ou não eram consideradas fundamentais para a qualidade ou sucesso do produto perante o usuário." (RINALDI, 2013).

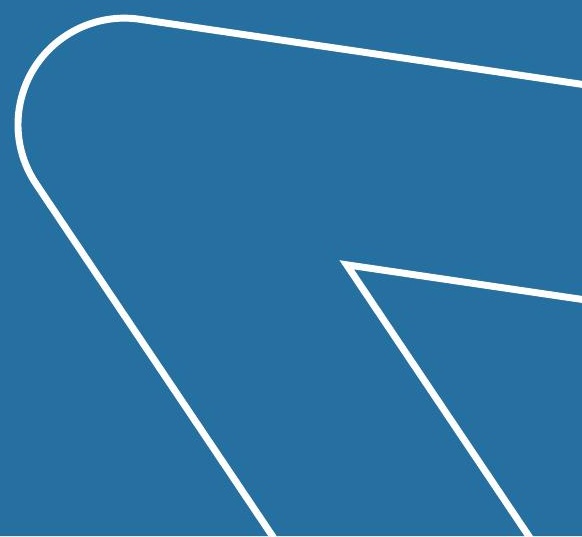


No design de superfície os elementos visuais também podem ser táteis, eles participam da composição visual garantindo a característica primordial de propagação do módulo. O módulo é a unidade básica da padronagem, pode ser definido como a menor área que inclui todos os elementos visuais que constituem o desenho. A composição visual (figura 3) depende da organização dos elementos dentro do módulo e da articulação entre os mesmos, gerando o padrão de acordo com a estrutura de repetição (RÜTHSCHILLING, 2008).

Figura 3 - Composição visual: módulo, padrão e estrutura de repetição
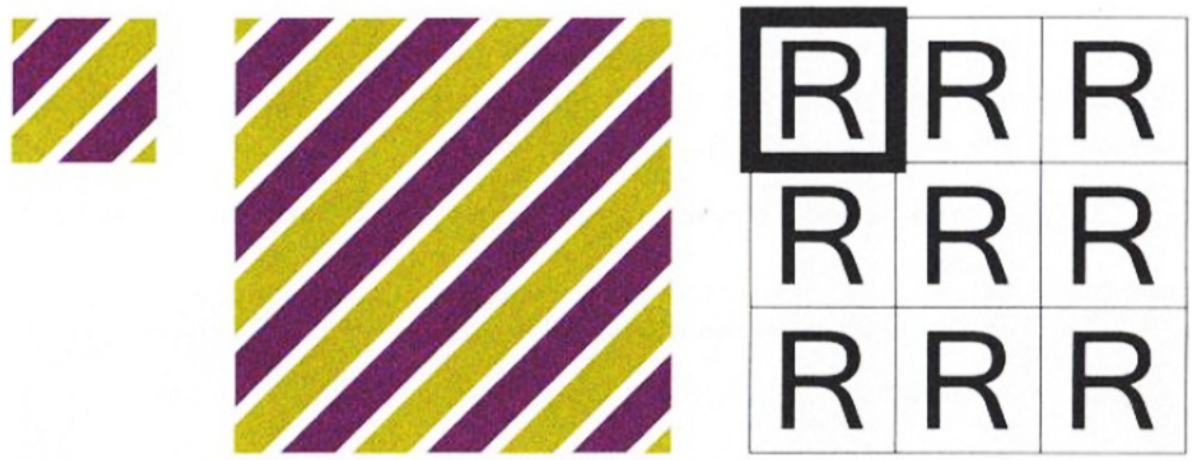

Fonte: Adaptado de Rüthschilling (2009).

O princípio do padrão é a propagação do módulo. A padronagem é uma composição visual que possui como característica fundamental a clara recorrência ou repetição de formas e demais elementos gráficos projetada para a aplicação sobre superfícies de produtos de revestimentos. São provenientes de diferentes processos industriais: seja impressa, aplicada, recortada, projetada, sempre diretamente ligada às características das superfícies dos materiais utilizados (GUBERT, 2011).

O encaixe dos motivos entre módulos é um estudo que prevê os pontos de encontro das formas entre um módulo e outro. Quando justapostos de acordo 
Proposta de metodologia para o aproveitamento...design de superfície

com o sistema de repetição definido, forma o desenho (figura 4). A noção de encaixe é regida pelos princípios de continuidade e contiguidade. A continuidade é a sequência ordenada e ininterrupta dos elementos visuais sobra a superfície. Já a contiguidade está relacionada com a harmonia visual dos encaixes, quando os módulos repetidos lado a lado, em cima e embaixo, formam novas relações entre figura e fundo, novos elementos visuais (RÜTHSCHILLING, 2009).

Figura 4 - Exemplos de diferentes sistemas de repetição de um mesmo módulo

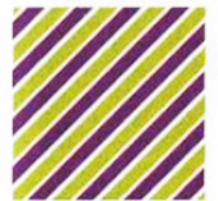

RR R R RR R R R R R R R R R R

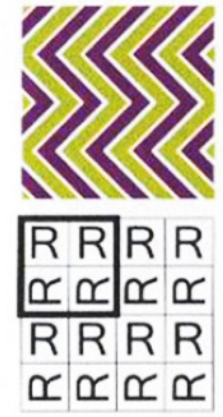

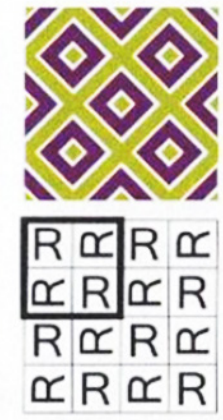

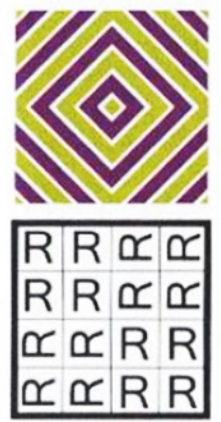

Fonte: Adaptado de Rüthschilling (2009).

O design de superfície pode ser representado a partir de três abordagens: representacional, constitucional e relacional. A primeira envolve a geometria e a representação gráfica, a segunda diz respeito aos materiais e aos procedimentos técnicos, e a última abrange relações de qualquer natureza estabelecidas entre o sujeito, o objeto e o meio. A abordagem constitucional está relacionada com o aspecto tridimensional, correspondendo ao volume do objeto ou artefato. Pode conduzir a interpretações de qualidades visuais, táteis e simbólicas diferentes, enfatizando a constituição do material. Deve-se considerar a estruturação física e visual e a constituição do material na definição das possibilidades estéticas do design de superfície (SCHWARTZ; NEVES; RÜTHSCHILLING, 2008). 
É possível aplicar grafismos sobre superfícies planas e também fazer aplicações volumétricas, expandindo o tratamento visual para fora do plano. Com relação à superfície tridimensional, Schwartz, Neves e Rüthschilling (2008) colocam que é importante a valorização da geometria, do desenho, formado no arranjo físico da composição a fim de explorar o potencial físico e plástico inerente do material. Ainda, destacam a importância de demonstrar graficamente a configuração da matéria no caso de texturas constituintes da própria matéria-prima.

As propriedades sensoriais intrínsecas dos materiais devem ser valorizadas. Calegari (2013) pesquisou a percepção dos designers com relação às características estéticas, simbólicas e práticas em compósitos biodegradáveis. Identificou que a visibilidade de elementos que autenticam a origem natural das matérias-primas é fundamental para o reconhecimento e a utilização de tais materiais. A percepção dos designers em relação aos aspectos simbólicos do material teve foco nas cores que remetem aos materiais naturais, na associação com o estilo rústico e o apelo ecológico devido a aparência destes materiais.

O design de superfícies tridimensionais tem caráter interdisciplinar, exige do designer o domínio dos materiais e técnicas que serão utilizados, compreensão do processo produtivo, análise da viabilidade econômica, do impacto social e ambiental, conhecimento do mercado, público-alvo e tendências (OLIVEIRA, 2012). As propriedades sensoriais dos materiais devem ser enfatizadas, elas expressam os elementos principais da superfície: figura, textura e contraste. No design de superfícies tridimensionais a relação de percepção dos sentidos é mais intensa: visual, a partir das cores, texturas e contrastes; tátil, a partir dos relevos; olfativa, nos materiais naturais.

O design de superfícies tridimensionais é uma alternativa para a produção de produtos com maior valor agregado, uma solução paliativa dentro da hierarquia dos resíduos. Os resíduos sólidos, em geral, possuem características heterogêneas 
Proposta de metodologia para o aproveitamento...design de superfície

NEJELISKI, D. M.; DUARTE, L. da C.

de constituição, propriedades e dimensões. O aproveitamento no design de superfície possibilita o uso de materiais com pequenas dimensões e com formatos distintos.

\section{PROPOSTA DE METODOLOGIA}

O projeto de um produto é uma atividade complexa que envolve profissionais, muitas vezes de áreas distintas, em uma série de tarefas a serem executadas simultânea e sequencialmente. A metodologia auxilia a organizar e hierarquizar as etapas do processo, definir as entradas e saídas em cada fase, fornece ferramentas de análise para a avaliação na tomada de decisões e assim, justifica e aprimora o desenvolvimento da proposta. Para Bürdek (2006), a utilização de métodos dá suporte para a pesquisa, avaliação, validação e otimização no design.A seleção de uma metodologia que contemple as especificidades de cada projeto pode ser decisiva no êxito do produto a ser desenvolvido.

O design de superfície se desenvolveu a partir do design têxtil (RUBIM, 2010), o que justifica o desenvolvimento de metodologias específicas na área, como o método de Oliveira (2012), que propõe utilizar estudos na área da biônica como referência para a criação de estampas têxteis, já Carvalho e Rüthschilling (2016) estimulam o processo criativo a partir da união de técnicas manuais e digitais de criação de módulos. A metodologia proposta por Mol (2014) tem como objetivo a transposição de elementos e valores culturais brasileiros para o design de superfícies. Com relação às superfícies tridimensionais, Dischinger e Kindlein Jr. (2010) desenvolveram uma metodologia para mensurar e analisar a percepção tátil dos usuários em diferentes materiais e texturas.

Neste contexto, Briede e Alarcón (2012) desenvolveram uma metodologia para o desenvolvimento de novos materiais, com o objetivo potencializar os 
aspectos visuais e formais de matérias-primas não convencionais. A valorização dos materiais se dá tanto no sentido de aprimorar as propriedades sensoriais, quanto nas possíveis repercussões nas propriedades físicas e mecânicas. A partir dos conceitos de uso de resíduos no design de superfície e valorização das propriedades sensoriais dos materiais, a metodologia de Briede e Alarcón (2012) foi adaptada para o presente trabalho. Assim, foi estruturada uma proposta de metodologia para o aproveitamento de resíduos no design de superfícies tridimensionais, que posteriormente podem ser utilizadas como revestimentos modulares ou como componentes de produtos. O foco deixa de ser o desenvolvimento de novos materiais e passa a ser o desenvolvimento de produtos (figura 5).

Figura 5 - Proposta de metodologia para o aproveitamento de resíduos no design de superfície

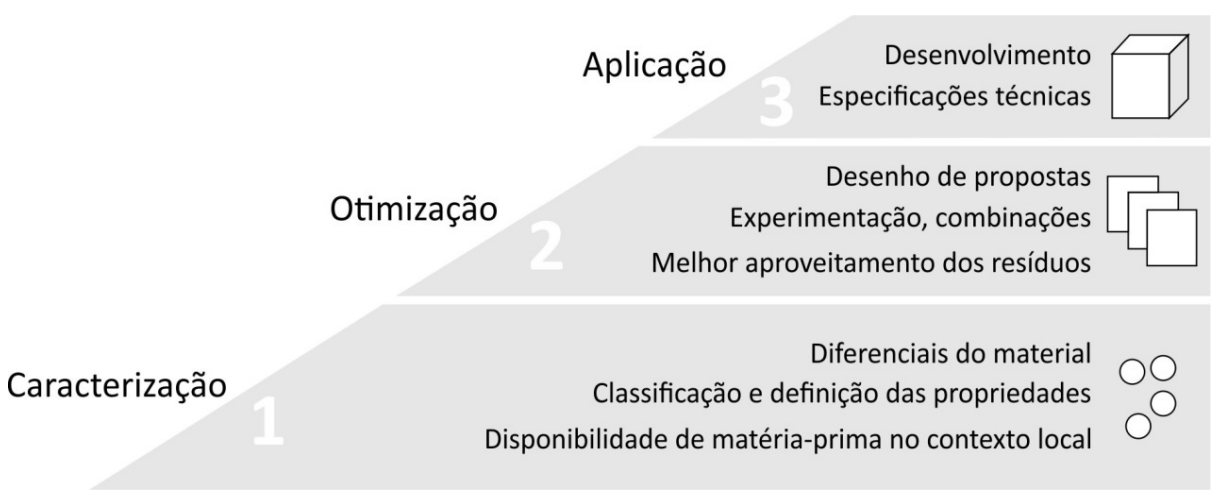

Fonte: Adaptado de Briede e Alarcón (2012).

A primeira etapa é de caracterização e envolve a definição do resíduo, a classificação, a especificação das principais propriedades e dos diferenciais estéticos. A seleção do resíduo deverá ser pautada principalmente pela disponibilidade, tanto em quantidade quanto em proximidade, é importante valorizar o uso de matérias-primas locais. O resíduo deve ser acessível, produzido em quantidade considerável e a partir de atividades locais. Na sequência é realizada a classificação, 
Proposta de metodologia para o aproveitamento...design de superfície

que tem como objetivo especificar a parcela que tem potencial para ser utilizada como matéria-prima. Em geral, resíduos sólidos são heterogêneos, compostos por elementos de tamanhos e formas diferentes, misturados com outros materiais e rejeitos. A classificação tem como resultado a divisão em grupos e subgrupos com características similares de tamanho, textura, cor, morfologia. O processo deve ser direcionado no sentido de aproveitar o máximo possível o resíduo, visto que o aproveitamento total nem sempre é viável.

Após a classificação são definidas as principais propriedades dos materiais. As propriedades físicas são àquelas inerentes à estrutura do material, como a densidade, o teor de umidade e de absorção de água. Já as propriedades mecânicas se referem ao comportamento do material quando submetido à ação de uma força, como tração, compressão ou elasticidade. Se a matéria-prima utilizada for convencional, estas informações podem ser facilmente encontradas na literatura. Entretanto, se for um material pouco explorado e utilizado, os ensaios deverão ser realizados de acordo com as normas vigentes. A definição das principais propriedades físicas e mecânicas do material é um ponto crucial do processo, pois vai direcionar as futuras aplicações no design de superfície.

No design, tão importantes quanto as propriedades técnicas, são as propriedades sensoriais dos materiais. Nesse sentido, a primeira etapa da metodologia se encerra com um tópico dedicado às características sensoriais, aqui chamados de diferenciais do material. A análise das propriedades sensoriais é subjetiva, está relacionada com aspectos pessoais como o estilo de vida e as referências de quem analisa. Por isso as considerações provavelmente vão variar de acordo com quem analisa o material. O objetivo desta parte é determinar quais as características que definem o material em termos de cores, texturas, morfologia, formas. A consistência do material, a percepção e sensação deste, e as possíveis evocações do contexto de origem são alguns dos aspectos que se desejam fortalecer e a partir deles gerar um vínculo afetivo com os usuários. 
A segunda etapa é de otimização e envolve o estudo do aproveitamento do material, a experimentação e o esboço de propostas de módulos. Após a classificação e a definição das principais propriedades do material, um quadro amplo de possíveis aplicações é delineado. Por exemplo, se o material é particulado poderá ser utilizado na composição de painéis aglomerados, se for fibroso poderá ser utilizado como matriz de compósitos, poderá ser tramado, enfim, a segunda etapa inicia com uma visão geral do potencial de uso do material. Com base nas informações da etapa anterior, é definido o melhor aproveitamento dos resíduos no design de superfície. Se o material for homogêneo e sólido, poderá ser utilizado em módulos de grandes dimensões, se for heterogêneo poderá ser reduzido a peças de dimensões reduzidas, se for fibroso pode ser feita uma trama ou pode ser utilizado um adesivo para unir as fibras. É um processo específico para cada material, onde a essência do mesmo deve ser respeitada.

Na sequência tem início a experimentação, fase criativa do processo. 0 objetivo é potencializar os aspectos visuais e formais das matérias-primas não convencionais, tanto no sentido de aprimorar as propriedades na perspectiva visual quanto as possíveis repercussões nas propriedades físicas e mecânicas. A manipulação do material é fundamental para compreender e explorar todas as possibilidades. Após a experimentação, as soluções mais interessantes são selecionadas e parte-se para o desenho de propostas de módulos. Nesta fase, as possibilidades de aplicações do material são afuniladas, com menos opções, mais específicas. O objetivo do desenho de propostas é explorar ao máximo diferentes configurações para os produtos que se enquadram nos requisitos definidos até o momento.

Por fim, a terceira etapa é de aplicação e envolve as especificações técnicas e o desenvolvimento de padrões. A partir das propostas de módulos geradas na etapa anterior, é selecionada àquela em que o material se destaca, considerando também a viabilidade de execução. Na sequência, têm início os estudos para as 
Proposta de metodologia para o aproveitamento...design de superfície

especificações técnicas, que variam de acordo com o nível de complexidade do produto. As especificações podem envolver estudos ergonômicos, de usabilidade, de funcionalidade, estudos de elementos de união, de montagem, de acordo com os requisitos. Após a definição de todos os detalhes do produto, é realizado o detalhamento técnico, a partir de desenhos técnicos, modelagem tridimensional e simulações de aplicações.

Por se tratar de uma metodologia para a valorização dos materiais, a confecção de modelos é fundamental para o estudo e uma melhor visualização da configuração do produto. Definidos os pormenores, parte-se para a última fase, de desenvolvimento, onde os módulos e padrões desenvolvidos são aplicados em produtos. Ao final, o design de superfície desenvolvido a partir do resíduo deverá ter características estéticas que evoquem o material, em que o usuário consiga identificar elementos de origem, deve carregar a simbologia do material, as principais características estéticas devem ser ressaltadas.

\section{CONSIDERAÇÕES FINAIS}

A problemática de geração excessiva de resíduos sólidos e o seu descarte incorreto é uma questão, muitas vezes, minimizada. Fato é que as consequências do descaso são generalizadas, afetam toda a sociedade. Do mesmo modo, a busca por soluções, sejam elas preventivas, paliativas ou de descarte, são de responsabilidade de todos atores sociais, pessoas físicas, jurídicas, governo. O caráter multidisciplinar do design possibilita uma análise ampla do contexto no processo de busca por soluções, o que permite desenvolver desde projetos pontuais até propostas de novos estilos de vida. Projetos com foco em promover o design para a sustentabilidade podem contribuir muito para a redução da geração de resíduos sólidos.

De todas as áreas do design, talvez o design de superfície seja o mais essencialmente multidisciplinar. Se desenvolve a partir de todos os suportes, sejam 
Projética, Londrina, v. 12, n. 2, p. 13-38, agosto 2021

digitais, gráficos ou físicos, do mesmo modo que pode ser produzido a partir de técnicas, materiais e processos diversos. Esse contexto favorece o aproveitamento de resíduos sólidos para a produção de produtos com maior valor agregado, pois são materiais heterogêneos. Ainda, o design de superfície auxilia a desfazer a percepção generalizada de que resíduos são materiais de menor valor. De acordo com Gomes (2011) isto acontece porque temos dificuldade em desassociar o sentimento negativo que existe em relação aos resíduos.

Considerando o caráter heterogêneo dos resíduos sólidos e o potencial de valorização dos materiais que o design de superfícies tridimensionais apresenta, foi proposta uma abordagem metodológica para facilitar o desenvolvimento de projetos integrando estas duas áreas. O foco da metodologia é na caracterização dos resíduos e definição das suas principais propriedades, para então partir para a experimentação. A terceira e última etapa, de aplicação, nada mais é do que a finalização do trabalho desenvolvido ao longo das outras duas etapas.

A caracterização e a experimentação são fundamentais para definir quais aspectos dos resíduos devem ser valorizados na criação dos módulos e dos padrões. O objetivo é que a metodologia auxilie na criação de projetos de design de superfície com foco nas propriedades sensoriais dos resíduos, de modo que os usuários possam identificá-los e criar uma associação positiva com o processo de aproveitamento do material. Por fim, as superfícies tridimensionais desenvolvidas podem ser o resultado em si, ou podem ser utilizadas como base no design de novos produtos. 
Proposta de metodologia para o aproveitamento...design de superfície NEJELISKI, D. M.; DUARTE, L. da C.

\section{REFERÊNCIAS}

1. ABRELPE, Associação Brasileira de Empresas de Limpeza Pública e Resíduos Especiais. Panorama dos resíduos sólidos no Brasil 2019. São Paulo, SP, 2019. Disponível em https://abrelpe.org.br/download-panorama-2018-2019/ acesso Dezembro 2019

2. ASHTON, Elisa Guerra. Design, inovação e sustentabilidade: estudo da reciclagem de produtos multi-materiais poliméricos sem separação prévia. 2017. Tese (Doutorado em Design) - Universidade Federal do Rio Grande do Sul, Porto Alegre, 2017.

3. ASHTON, Elisa Guerra. Analysis of footwear development from the design perspective: Reduction in solid waste generation. Strategic Design Research Journal, [s. I.], v. 11, n. 1, p. 2-8, Jan. 2018.

4. BACK, Nelson et al. Projeto integrado de produtos: planejamento, concepção e modelagem. Barueri: Manole, 2008.

5. BRASIL. Lei $\mathbf{n}^{\circ} \mathbf{1 2 . 3 0 5}$, de 02 de agosto de 2010. Institui a Política Nacional dos Resíduos Sólidos e dá outras providências. Brasília, DF: Presidência da república, 2010.

6. BRIEDE, Carlos Juan; ALARCÓN, Jimena. Estrategias sutentables aplicadas al contexto regional: disseño de tableros de madera y materias primas no convencionales para revestimento decorativo. Interciencia, Caracas, v. 37, n. 12, p. 927-933, Jan. 2012. 
Proposta de metodologia para o aproveitamento...design de superfície NEJELISKI, D. M.; DUARTE, L. da C.

14. GUBERT, Marjorie Lemos. Design de interiores: a padronagem como elemento compositivo no ambiente contemporâneo. 2011. Dissertação (Mestrado em Design) - Universidade Federal do Rio Grande do Sul, Porto Alegre, 2011.

15. MANZINI, Ezio. A matéria da invenção. Lisboa: Centro Português de Design, 1993.

16. MANZINI, Ezio; VEZZOLI, Carlo. O desenvolvimento de produtos sustentáveis: os requisitos ambientais dos produtos naturais. São Paulo: EDUSP, 2008.

17. MOL, Iara Aguiar. Superfícies de um lugar: proposição de método de ensino para design de superfície a partir de valores culturais brasileiros. 2014. Dissertação (Mestrado em Design) - Universidade do Estado de Minas Gerais, Belo Horizonte, 2014.

18. OLIVEIRA, Monique Aline Arabites de. Design de superfície: proposta de procedimento metodológico para criação de estampas têxteis com referência em elementos naturais. 2012. Dissertação (Mestrado em Design) Universidade Federal do Rio Grande do Sul, Porto Alegre, 2012.

19. RINALDI, Ricardo Mendonça. A intervenção do design nas superfícies projetadas: processos multifacetados e estudos de caso. 2013. Tese (Doutorado em Design) - Faculdade de Arquitetura, Artes e Comunicação, Universidade Estadual Paulista “Julio de Mesquita Filho, Bauru, 2013.

20. RUBIM, Renata. Desenhando a superfície. São Paulo: Editora Rosari, 2010. 
Projética, Londrina, v. 12, n. 2, p.13-38, agosto 2021

21. RUTSCHILLING, Evelise Anicet. Design de superfície. Porto Alegre: Editora da UFRGS, 2009.

22. SCHWARTZ, Ada Raquel Doederlein; NEVES, Aniceh Farah; RUTSCHILLING, Evelise. Design de superfície: por uma abordagem geométrica e tridimensional. Educação Gráfica, Bauru, p. 146-163, 2008. Edição especial.

23. WALTER, Yuri. O conteúdo da forma: subsídios para a seleção de materiais e design. 2006. Dissertação (Mestrado em Desenho Industrial) - Faculdade de Arquitetura, Artes e Comunicação, Universidade Estadual Paulista Júlio de Mesquita Filho, Bauru. 2006.

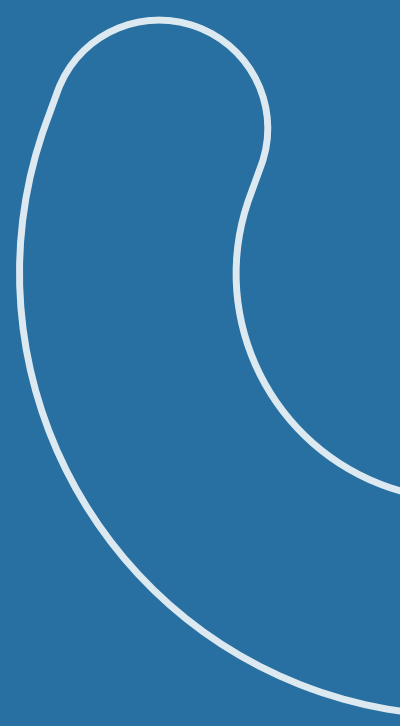

